\title{
Simple and Robust Direct Drive Wave Power Generation System Using Dielectric Elastomers
}

\author{
Seiki Chiba ${ }^{1}$, Mikio Waki ${ }^{2}$, Koji Fujita $^{3}$, Koichi Masuda ${ }^{4}$ and Tomoki Ikoma ${ }^{4}$ \\ 1. Chiba Science Institute, Meguro Ward, Tokyo 152-0023, Japan \\ 2. Wits Inc., Sakura City, Tochigi 329-1334, Japan \\ 3. Institute of Space and Astronautical Science, Japan Aerospace Exploration Agency, Sagamihara City, Kanagawa 252-5210, Japan \\ 4. Department of Oceanic Architecture and Engineering, CST, Nihon University, Funabashi City, Chiba 274-8501, Japan
}

\begin{abstract}
DEs (dielectric elastomers), a type of electroactive polymer, show considerable promise for harvesting energy from wind, ocean waves, water currents, or even from human motion. Their energy density and efficiency of conversion make for simple, low cost, and robust generators where an electroactive polymer transducer is directly driven by the up-and-down motions of waves. Over the past few years, we have conducted various tests to validate DE wave power generators. In our 2010 test, a DE generator generated electricity even with comparatively small wave heights. Generator performance over a longer period of time (50 minutes) was evaluated in our present test. In the 2010 test, the system was not able to automatically respond to changes in sea level because of its mooring. The present system used a sunken horizontal plate, which enabled it to create the needed reaction forces and respond to sea level changes. This method of mooring generated electric power even in deep water.
\end{abstract}

Key words: Wave power generation, water power generation, artificial muscle actuators, dielectric elastomers, direct drive, DE transducer.

\section{Introduction}

Increasing world energy demands, increased awareness of the potential threat of global climate change, and reliance on fossil fuels from increasingly scarce and unreliable sources have created a growing need for clean, renewable energy sources. A secure energy supply is possible, if environmental sources are coupled to appropriate energy harvesting systems [1]. The hydrokinetic energy in flowing river streams, tidal currents or other artificial water channels are also important sources of renewable power [2]. Intermittent sources, such as wind and solar, have already proven their value on the world stage. Wave power generation is far less proven, but has attracted attention as a particularly desirable form of renewable energy [3].

Existing wave generators based on electromagnetic

Corresponding author: Seiki Chiba, Ph.D., CEO, research field: dieleastic elastomers. generators are large and expensive, and cannot generate electric power efficiently from small waves, limiting their widespread usage [4, 5]. Energy harvesting systems can use piezoelectric materials. Due to the nature of the piezoelectric response, and the cost of the materials, these generators tend to be used only for small devices that harvest energy from higher frequency sources such as mechanical vibrations [6-9].

Wave power generators using DE (dielectric elastomer) transducers, a novel method to harvest renewable energy $[10,11]$, also known as "artificial muscles" because of their functional similarity to natural muscles when operated in reverse as actuators, may be able to solve these problems.

These artificial muscles create electric power by their expansion and contraction [11]. Because dielectric elastomer is light, inexpensive, and easily formed into multilayered structures, it makes a simple and robust direct drive wave power system which is 
economically viable [10-12].

This paper shows that several practical issues in implementing artificial muscle generators can be overcome. Specifically, the following issues were examined: (1) the long-time power generation performance for the practical use of DEs, (2) the effect of a mooring method developed to automatically respond to the change in the sea level, and (3) the possibility of power generation in deep water using this mooring method.

\subsection{Background on DE Artificial Muscle}

$\mathrm{DE}$ is a new transducer technology which uses rubber-like polymers called elastomers as actuator materials [13-15]. The core element of DE is a simple structure comprised of a thin elastomer sandwiched between flexible electrodes. When a voltage difference is applied across the electrodes, they attract each other by electrostatic forces (Coulomb forces). This attraction leads to a thickness-wise contraction and planar expansion of the elastomer. DE film can be made using several well-known techniques, including spin coating, dip coating and casting [14].

The use of a DE actuator in the reverse mode, in which deformation of the elastomer by external mechanical work is used to generate electrical energy, is gaining attention [16-19]. Jean-Mistral et al. [19] presented a DEG (dielectric elastomer generator) which generated a very small energy from human motion. Koh et al. [20] showed that various models of failure, including electrical breakdown, electromechanical instability, loss of tension, and rupture by stretching, defined a cycle of maximal energy of conversion. Huang et al. [21] claimed that they had achieved significant improvement in energy density with power density using equi-biaxial stretching.

Kussel et al. [22] investigated a passive DEG harvesting system which used only diodes at the generator level. The performance of a DEG composed of an annular membrane deformed out-of-plane by an external oscillating loading that was investigated employing a hyper-electro-elastic model with parameters adjusted to simulate the behavior of material such as an acrylic elastomer and a type of natural rubber [23]. Zhou et al. [24] claimed that a material viscoelasticity had a significant effect on the electromechanical coupling and dynamic performance.

\subsection{DEGs (Dielectric Elastomer Generators)}

The principle of operation of the generator mode is the transformation of mechanical energy into electric energy by deformation of the DE. Functionally this mode of operation resembles piezoelectricity, but its power generation mechanism is fundamentally different. With DE, electric power can be generated even by a slow change in the shape of DE $[8,10]$, while for piezoelectric devices higher-frequency impulsive mechanical forces are needed to generate the electric power [6]. Also, the amount of electric energy generated on a per mass basis and conversion efficiency from mechanical to electrical energy can be greater than that from piezoelectricity $[9,25,26]$. Fig. 1 shows the operating principle of DE power generation.

A typical energy harvesting cycle is as follows: (1) Application of mechanical energy to DE to stretch it causes compression in thickness and expansion of the surface area. (2) A voltage is applied to the membrane. The applied energy is produced and stored on the polymer as electric charge. (3) The stretching forces are removed. The recovery force of the DE acts to restore the original thickness and to decrease the in-plane area. At this time, the electric charge is pushed out to the electrode direction. This change in electric charge increases the voltage difference, resulting in an increase of electrostatic energy.

We can calculate the energy generated for such a cycle. The capacitance of the DE is

$$
C=\varepsilon_{0} \varepsilon \frac{S}{d}=\varepsilon_{0} \varepsilon \frac{b}{d^{2}}
$$




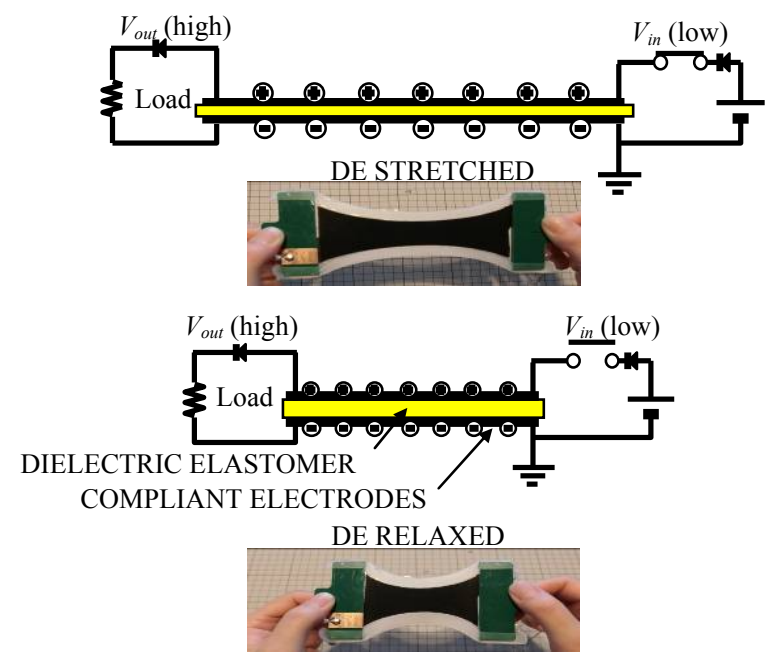

(a) Operating principle of dielectric elastomer power generation; the DEG is basically a stretchable capacitor. If a charge is applied to the DEG in the stretched state then work done by the contracting elastomer is converted into electrical energy.

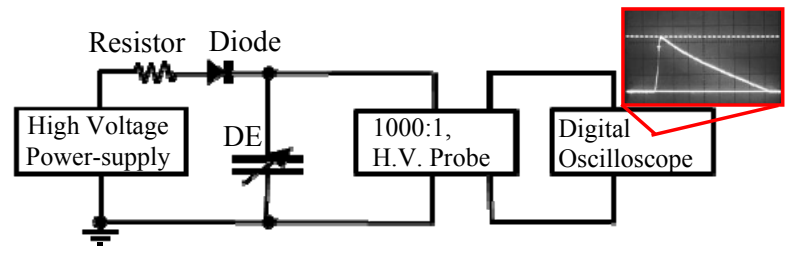

(b) Voltage during the relaxation of a DEG and measurement circuit and a typical oscilloscope trace during DE contraction.

Fig. 1 Operating principle of DE power generation, and voltage measurement circuit.

where, $\varepsilon_{0}$ is the dielectric permittivity of free space, $\varepsilon$ is the dielectric constant of the polymer film, $S$ is the surface area of the active polymer, $d$ is its thickness, and $b$ is its volume. The second equality in Eq. (1) can be written because the volume of elastomer is essentially constant, i.e.,

$S d=b=$ constant.

The energy output of a DEG per cycle of stretching and contraction is

$$
\mathrm{E}=0.5 \mathrm{C}_{1} \mathrm{~V}_{\mathrm{b}}^{2}\left(\frac{\mathrm{C} 1}{\mathrm{C} 2}-1\right)
$$

where, $C_{1}$ and $C_{2}$ are the total capacitances of the $\mathrm{DE}$ films in the stretched and contracted states, respectively, and $V_{b}$ is the bias voltage.

Regarding time changes with respect to voltages, the electric charge $Q$ on a dielectric elastomer film can be considered to be constant over a short period of time and in the basic circuit. Since $V=Q / C$, the peak voltages in the stretched state and the contracted state can be expressed as $V_{1}$ and $V_{2}$, respectively, and the following equation is obtained:

$$
\mathrm{V}_{2}=\frac{\mathrm{Q}}{\mathrm{C}_{2}}=\left(\frac{\mathrm{C}_{1}}{\mathrm{C}_{2}}\right)\left(\frac{\mathrm{Q}}{\mathrm{C}_{1}}\right)=\left(\frac{\mathrm{C}_{1}}{\mathrm{C}_{2}}\right) \mathrm{V}_{1}
$$

Since $C_{2}<C_{1}$, the contracted voltage is higher than the stretched voltage, corresponding to the energy argument noted above. The higher voltage can be measured and compared with predictions based on dielectric elastomer theory [27]. In general, experimental data based on high impedance measurements are in excellent agreement with predictions [27].

\subsection{Recent Challenges of Wave Power Generators} Using Dielectric Elastomers

A proof-of-principle DE buoy generator was developed by Chiba et al. beginning in 2005 [10]. This generator produced over $5 \mathrm{~J} /$ stroke at $0.3 \mathrm{~Hz}$ using only about $40 \mathrm{~g}$ of DE material. LED lights, such as might be used for navigation buoys, were able to flash continuously in a small wave tank using only $10 \mathrm{~cm}$ waves.

The world's first marine experiment into power generation by DEGs using natural sea waves was carried out in August 2007 in Tampa Bay, Florida, USA [11]. This generator had $150 \mathrm{~g}$ of DE material. The maximum measured electrical output, verified in laboratory tests, was $12 \mathrm{~J} /$ stroke. However, wave heights were on the order of few centimeters, which made it very difficult to carry out tests using natural waves. On occasion the weather generated waves 10 centimeters high. Even with the 10 centimeter waves, we were able to generate the peak energy of $3.6 \mathrm{~J}$ at a bias voltage of $2,000 \mathrm{~V}$. This generator used a proof-mass to provide the mechanical forces that stretch and contract the DE generator.

Fig. 2 shows a buoy system using DE generators in December 2008 [28]. In December 2008, oceanic tests were carried out in California, USA, and it was 
confirmed that generated electric power was able to be stored in a battery [28]. Fig. 3 shows a buoy system using DE generators in December 2008. In November 2010, we carried out marine tests for electric power generation using a fairly small buoy of $90 \mathrm{~cm}$ in diameter at Suzaki Port in Izu Peninsula (located 200 $\mathrm{km}$ south-west of Tokyo, Japan). This electric power generation system was portable. It could easily be mounted on the side of a ship, shore protection, or seawalls [29]. Even with waves of comparatively small wave height, the system was able to generate electricity.

Recently, Moretti et al. [30] and Vertechy et al. [31] also showed that one of the most promising applications for DEGs was in the field of wave energy harvesting.

\subsection{Improvement of Small Buoy Generation System in the Present Test}

In the experiments at sea discussed above, the measurement time of the power generation was relatively

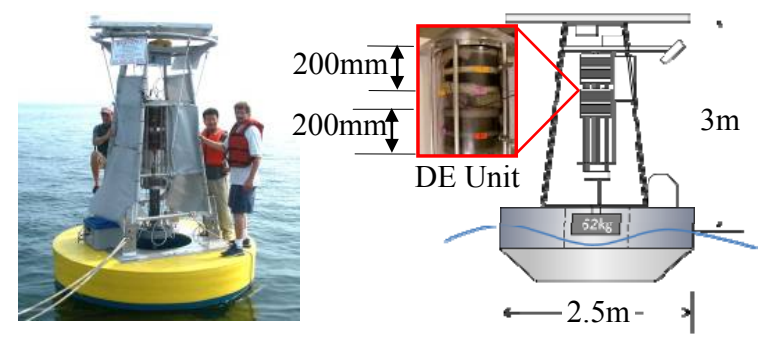

Fig. 2 DE wave generator system on the buoy used in August 2007.

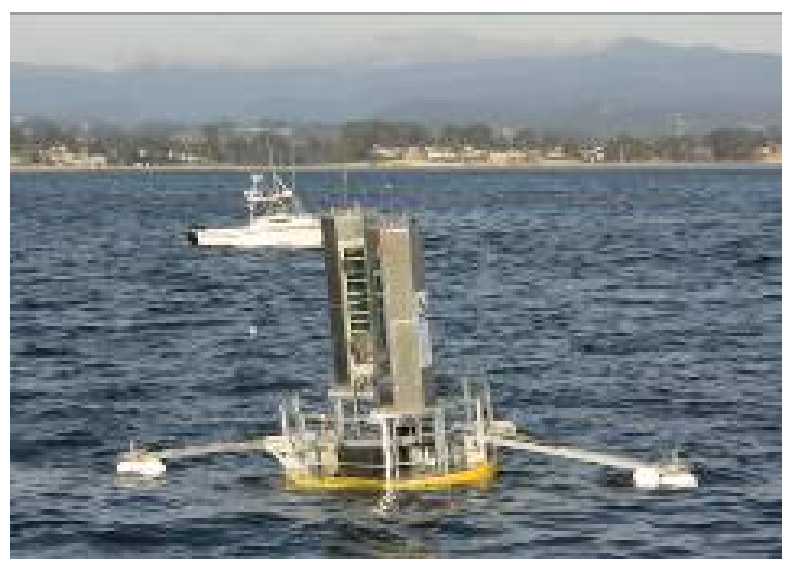

Fig. 3 A buoy system using DE generators in December 2008. short. Consequently, evaluation of generation over a longer period of time was carried out in the present test. In the 2010 test, the mooring method of the system did not automatically respond to the change in the sea level. In the present test, we examined whether mooring with a sunken horizontal plate could respond to changes in sea level. Furthermore, we examined whether this mooring method can generate electric power even in deep water. The experimental set-up and procedure of these experiments is discussed below.

\section{Experimental Set-up}

The DE artificial muscle material used for the power generation module in this experiment weighed 4.6 g. The polymer was an acrylic elastomer $(3 \mathrm{M}$ Corp., VHB4910). The electrode was based on carbon black with a polymer binder [9]. The electrodes were made by mixing carbon black and a polymer binder (silicone adhesive) in toluene $\left(\mathrm{C}_{7} \mathrm{H}_{8}\right)$, and dipping polymer into this solution. The average size of the carbon black particles is $50 \mathrm{~nm}$. The average thickness of the polymer is $500 \mu \mathrm{m}$. The average thickness of the electrodes is $15-20 \mathrm{~nm}$. The muscle formed a tubular shape that pulled into a smaller diameter at the center ( $26 \mathrm{~cm}$ in diameter and $12 \mathrm{~cm}$ in height). Fig. 4 shows drape-type, single layered DE artificial muscle, and DEG on the test buoy and mooring equipment set near shore protection.

This type of transducer is known as a "draped roll". When a voltage of $3,000 \mathrm{~V}$ was applied to the artificial muscle, its maximum power generation was approximately $274 \mathrm{~mJ}$. The stroke from stretched to relaxed states was $6 \mathrm{~cm}$.

In the present system, a sunken horizontal plate which allows the generator to respond to changes in sea level was fixed to the power generation buoy. As waves acted both from the difference in the buoyancy with the buoy and the sunken horizontal plate, the buoy is easily buoyant, and there is also much resistance of no water when rising. Therefore the 
distance between the buoy and the plate becomes bigger. The mooring wire between them was pulled accordingly, and DE in the buoy was transformed.

This method enabled the development of a DE system which can generate electric power for a long time. It is also possible to generate power in deep water using this method. Fig. $4 \mathrm{~b}$ shows the buoy and mooring system. The sunken horizontal plate is square of $950 \mathrm{~mm}$ and a thickness of $3 \mathrm{~mm}$. It was held with the buoy moored from four corners at a fixed depth of water. The artificial muscle was directly stretched by the up-down motions of the buoy due to waves.

In the preset test period, the average wave-height was $0.07-0.12 \mathrm{~m}$, and the average wave-period was 5.7-7.6 sec. Sea wave conditions were not ideal for power generation. The long-period waves which are effective for power generation were less common than

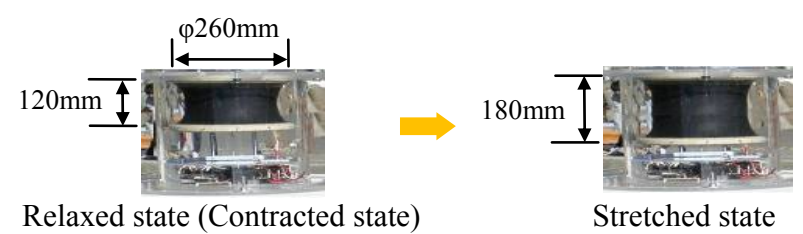

(a) Drape-type, single layered DE artificial Muscle.

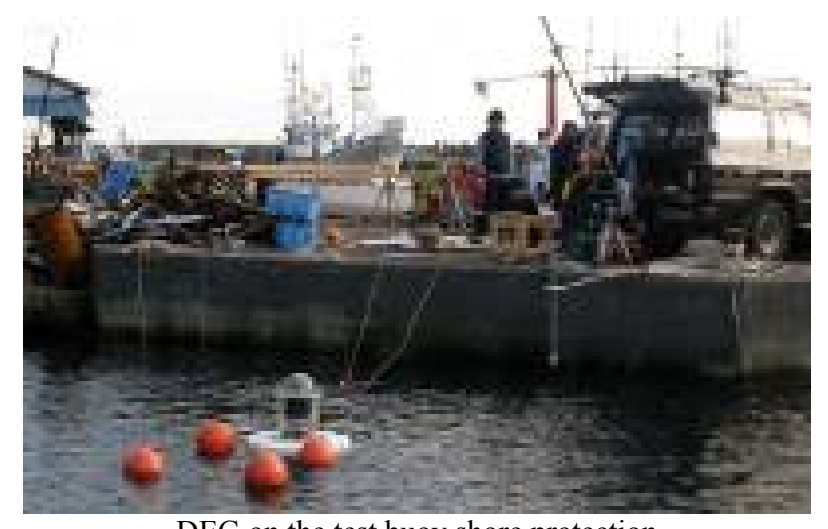

DEG on the test buoy shore protection
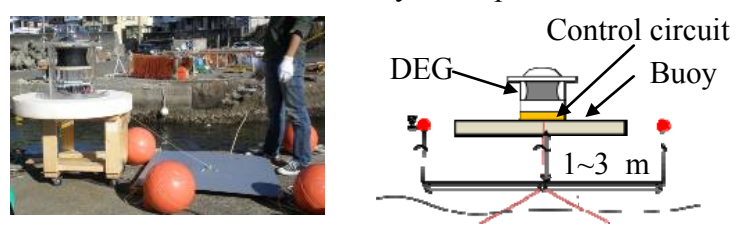

Mooring equipment and a sunken horizontal plate

(b) DEG on the test buoy (photo) and mooring equipment set near shore protection.

Fig. 4 Drape-type, single layered DE artificial muscle, and DEG on the test buoy and mooring equipment set near shore protection. those in the 2010 test. This present test was carried out from December 9 to December 14, 2015.

The electric power $(E)$ generated was estimated by the following method:

(1) The relation $C_{1}=V_{2} C_{2} / V_{1}$ is derived from Eq. (3), and then by introducing $C_{1}$ into Eq. (2), the electric power generated is obtained,

$$
\mathrm{E}=0.5 \mathrm{~V}_{1} \mathrm{~V}_{2} \mathrm{C}_{2}\left(\frac{\mathrm{V}_{2}}{\mathrm{~V}_{1}}-1\right)
$$

(2) Using Eq. (4) and the values of $C_{2}$ and $V_{2}$, the generated electric power can be determined.

(3) The values of $C_{2}$ and $V_{2}$ were obtained as follows:

(i) The voltage $\left(V_{2}\right)$ between the electrodes on both surfaces of the DE in its contracted state was measured at each wave period as shown in Fig. 4a contracted state [28].

(ii) The capacitance $\left(C_{2}\right)$ of the DE in the contracted state was also measured at each wave period as shown in Fig. 4a contracted state [28].

Fig. 5 shows measurement circuit of a voltage of $\mathrm{DE}$ in a contracted state, and measurement circuit of a capacitance of DE in the contracted state.

\section{Result and Discussion}

In the present test, the distances between the generator buoy and the sunken horizontal plate were $1 \mathrm{~m}$ and $3 \mathrm{~m}$. In addition, a test in which the horizontal plate was set on the sea bottom was also included. Figs. 6a

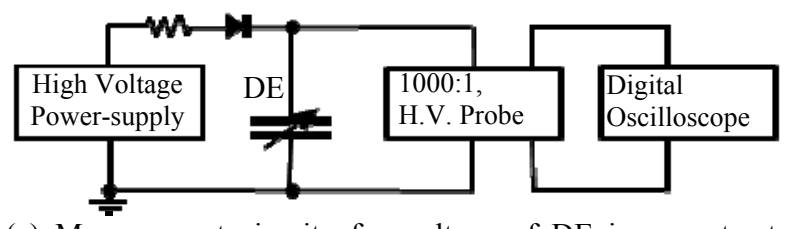

(a) Measurement circuit of a voltage of DE in a contracted state.

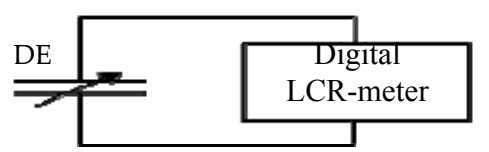

(b) Measurement circuit of a capacitance of DE in a contracted state.

Fig. 5 Measurement circuit of the voltage of $D E$ in a contracted state, and measurement circuit of the capacitance of DE in the contracted state. 


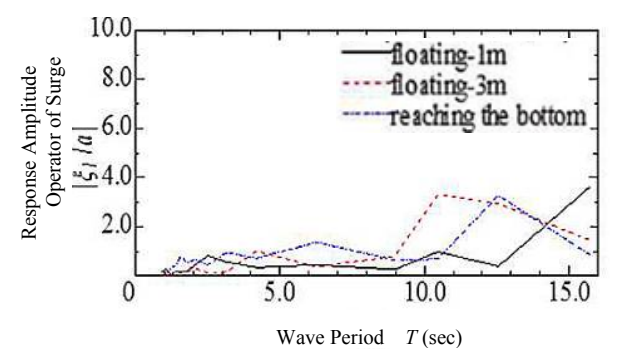

(a) Measurements from 14:48, December 10.
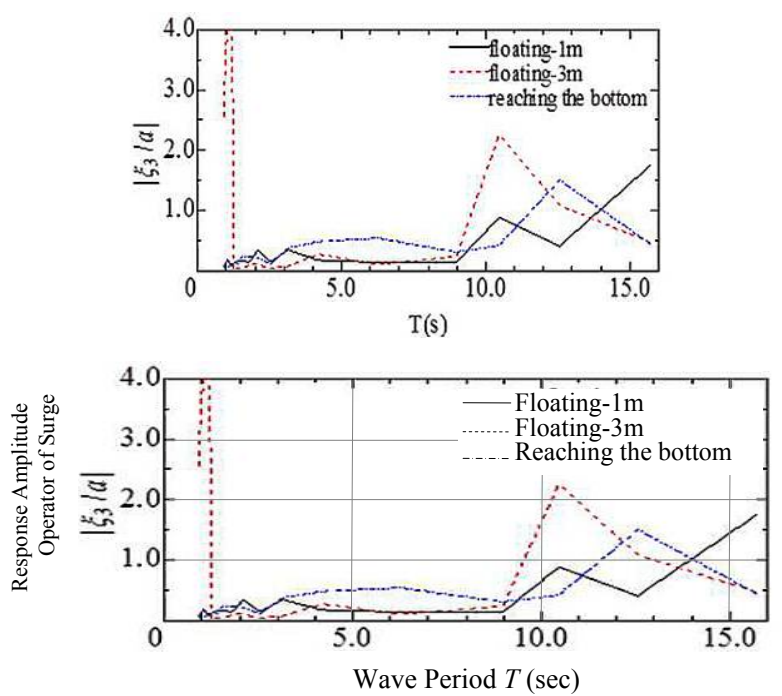

(b) Measurements from 13:47, December 12.

Fig. 6 Response amplitude operators of surge motion as a function of wave period, $T$.

and $6 \mathrm{~b}$ show response functions measured for each case. This was measured with a laser wave height meter and a 3-D accelerometer attached to the buoy. The functions are displacement response functions, which are calculated from the acceleration response functions estimated from the power spectra of the waves.

From these experiments, if the distance between the generator buoy and the sunken horizontal plate is about $3 \mathrm{~m}$, the performance is almost equal to that for the case in which the plate is set on the sea bottom. However, in the case of the 1-m distance, the motions of the buoy were less for the incident waves of long periods. This result is probably because the horizontal plate became unstable by the additional weight against incident waves, i.e., the horizontal plate was moved by the power of the incident waves acting on the generator buoy, resulting in a reduction of the momentum of the buoy itself.
For the case in which the horizontal plate was set on the sea bottom, the amount of generated power was measured for 50 minutes beginning at 14:48 on December 12. The $14 \mathrm{~J}$ of electrical energy was obtained at a bias voltage of $1,900 \mathrm{~V}$ and about $30 \mathrm{~J}$ was obtained at 3,000 V. Fig. 7 shows the total energy generation during 50 minutes in case of bias voltage of $1,900 \mathrm{~V}$ and $3,000 \mathrm{~V}$.

On the other hand, for the case in which the horizontal plate was fixed at a distance of $3 \mathrm{~m}$ below the buoy, the amount of generated power was $7.5 \mathrm{~J}$ for 63 minutes in the test of 13:47 December 12. Although

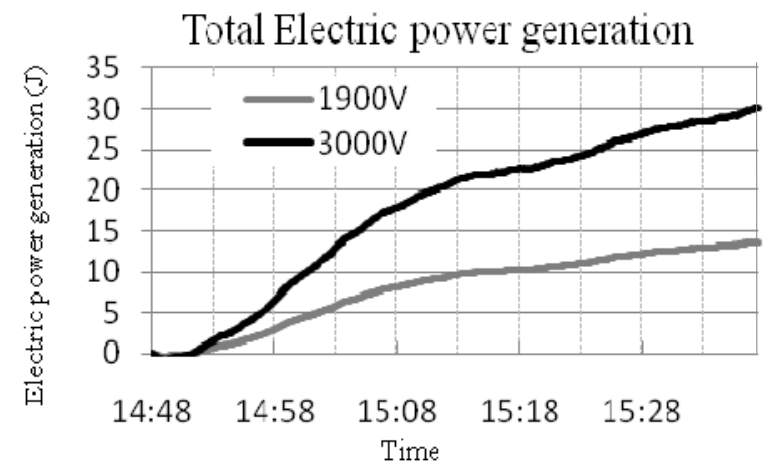

Fig. 7 Total energy generation during 50 minutes in case of bias voltage of $1,900 \mathrm{~V}$ and $3,000 \mathrm{~V}$.

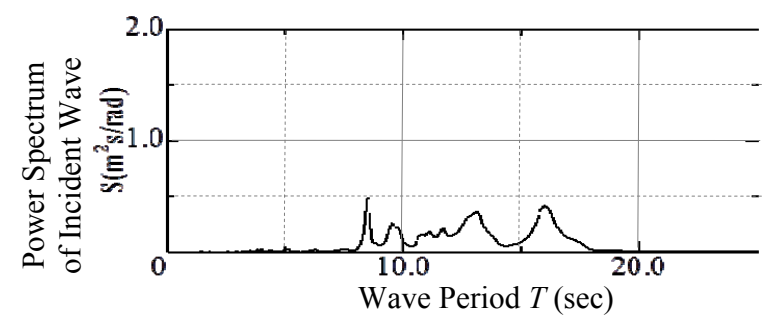

(a) Power spectrum of incident random wave at experimental site in 14:46.

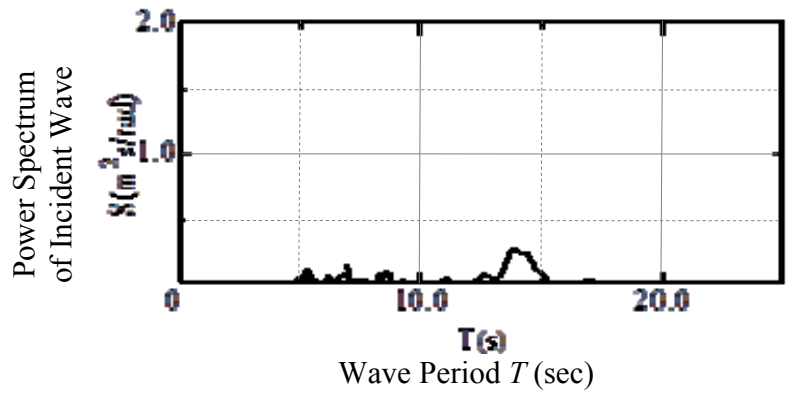

(b) Power spectrum of incident random wave at experimental site in 14:24.

Fig. 8 Power spectrum of incident random wave at experimental site at 14:46 and 14:24. 
the sea conditions were different for the two December 12 tests, it appears that power generation was indeed possible using a sunken horizontal plate, but the amount of power generated was less than the case in which the buoy was moored to the sea bottom.

In the test in which the plate is set on the sea bottom, the effective wave-height was $0.17 \mathrm{~m}$, and the effective wave-period was $4.5 \mathrm{sec}$. In the test with the $3 \mathrm{~m}$ depth of the plate, the effective wave-height was $0.09 \mathrm{~m}$ and the effective wave-period was $10.9 \mathrm{sec}$. The power spectra of incident waves during the test are shown in Figs. 8a and $8 \mathrm{~b}$.

\section{Conclusion}

Our results discussed above show that DE power generation is a renewable energy technology with great potential.

(a) We successfully fabricated a smaller portable system for electric power generation that could be used in a small harbor.

(b) We reconfirmed that wave power generation was possible using a small buoy containing the draped roll type $\mathrm{DE}$ in the harbor with small-amplitude waves.

(c) When the buoy-mounted DE power generation unit was employed, even in the harbor with small waves, it generated enough electrical energy to power small LED units.

(d) When a production of electricity was evaluated for 50 minutes, $14 \mathrm{~J}$ was obtained with the bias voltage $1,900 \mathrm{~V}$, and $30.1 \mathrm{~J}$ was obtained at 3,000 V.

(e) A system with a sunken horizontal plate can generate electric power. This method enables electric power generation even in deep sea.

In this study, a single layered DE generation module was employed due to our limited budget. Incorporating a greater number of DE layers in each module would increase the power generated by each unit. When a number of such modules are used at the same time, more electrical energy can easily be generated.
We plan to further investigate more effective structures and methods for harvesting wave energy. In late 2018, we plan to carry out full-scale ocean experiments using an improved buoy-mounted DE power generation unit that will enable a power output level of $400 \mathrm{~J}$. A $40 \mathrm{~J}$ device is being manufactured based on the $12 \mathrm{~J}$ model mentioned in chapter 1.2. Ten devices will become one cluster, as a $400 \mathrm{~J}$ model.

The next goal is to make a $2 \mathrm{~kW}$ power generation unit in late 2019. The $200 \mathrm{~J}$ model will be made based on the knowledge of $40 \mathrm{~J}$ model, and 20 of these models will be used as a cluster with a $2 \mathrm{~kJ}$ capacity.

Such a cluster could effectively generate electricity from different directions of waves with different size wave heights.

\section{References}

[1] Krajačić, G., Duić, N., and Carvalho, M. G. 2011. "How to Achieve a $100 \%$ RES Electricity Supply for Portugal?" Applied Energy 88 (2): 508-17.

[2] Khan, M. J., Bhuyan, G., Iqbal, M. T., and Quaicoe, J. E. 2009. "Hydrokinetic Energy Conversion Systems and Assessment of Horizontal and Vertical Axis Turbines for River and Tidal Applications: A Technology Status Review." Applied Energy 86 (10): 1823-35.

[3] U.S. Department of Energy, Energy Efficiency and Renewable Energy (EERE), World Energy Council. Accessed March 21, 2017. http://www.eere.energy.gov.

[4] Miyazaki, T., and Osawa, H. 2007. "Search Report of Wave Power Devices." In Proceedings of the 2007 Spring Conference of the Japan Society of Naval Architects and Ocean Engineers, 43-6. (In Japanese)

[5] Kiura, K. (Ed.), et al. 2009. New Energy Technology Outlook: Electronic Journal. (In Japanese)

[6] Ashida, K., Ichiki, M., Tanaka, M., and Kitahara, T. 2000. "Power Generation Using Piezo Element: Energy Conversion Efficiency of Piezo Element." In Proc. of JAME Annual Meeting, 139-40.

[7] Zurkinden, A., Campanile, F., and Martinelli, L. 2007. "Wave Energy Converter through Piezoelectric Polymers." In Proc. of COMSOL Users Conference 2007.

[8] Jean-Mistral, C., Basrour, S., and Chaillout, J. 2010. "Comparison of Electroactive Polymer for Energy Scavenging Applications." Smart Materials \& Structures 19 (19).

[9] Xuan, Y., Shuai, C. G., Gao, Y., and Zhao, Z. H. 2016. "Application Review of Dielectric Electroactive Polymers (DEAPs) and Piezoelectric Materials for 
Vibration Energy Harvesting." J. of Physics; Conf. Series 744 (1), 012077. DOI: 10.1088/1742-6596/744/1/01 12077.

[10] Chiba, S., Pelrine, R., Kornbluh, R., Prahlad, H., Stanford, S., and Eckerle, J. 2007. "New Opportunites in Electric Generation Using Electroactive Polymer Artificial Muscle (EPAM)." Journal of the Japan Institute of Energy 86 (86): 743-7.

[11] Chiba., S., Waki, M., Pelrine, R., and Kornbluh, R. 2008. "Innovative Power Generators for Energy Harvesting Using Electroactive Polymer Artificial Muscles." In Proc. SPIE 6927, Electroactive Polymer Actuators and Devices (EAPAD) 2008, 692715, San Diego, CA. DOI: $10.1117 / 12.778345$.

[12] Chiba, S., Kornbluh, R., Pelrine, R., and Waki, M. 2008. "Low-cost Hydrogen Production from Electroactive Polymer Artificial Muscle Wave Power Generators." In Proceedings of 17th World Hydrogen Energy Conference 2008, 214-7.

[13] Pelrine, R., and Chiba, S. 1992. In Proceedings of Third International Symposium on Micromachine and Human Science.

[14] Kornbluh, R., Pelrine, R., Joseph, J., Heydt, R., Pei, Q., and Chiba, S. 1999. "High-field Electrostriction of Elastomeric Polymer Dielectrics for Actuation." In Proc. SPIE 3669, Smart Structures and Materials 1999: Electroactive Polymer Actuators and Devices, 149. DOI: 10.1117/12.349672.

[15] Pelrine, R., Kornbluh, R., Prahlad, H., and Chiba, S. 2002. Trans. IEE of Japan, 122, 2, pp. 97. NAID: 10007792430 , NCID: AN10522634X, ISSN: 13418939, NEL: Z-16B380.

[16] Chiba, S., et al. 2007. "Extending Applications of Dielectric Elastomer Artificial Muscle." In Proc. SPIE 6524, Electroactive Polymer Actuators and Devices (EAPAD) 2007, San Diego, CA, 6524, 24. DOI: 10.1117/12.728671.

[17] Pelrine, R., Kornbluh, R., Prahlad, H., and Chiba, S. 2004. "Silicon to Silicone: Stretching the Capabilities of Micromachines with Electroactive Polymers." In IEEJ Trans SM 124 (8), pp. 124. DOI: Org/10.1541/ieejsmas.124.266.

[18] Chiba, S., Waki, M., Kornbluh, R., and Pelrine, R. 2011. "Current Status and Future Prospects of Power Generators Using Dielectric Elastomers." Smart Materials and Structures, 20 (12), 124006, pp. 1-7. DOI: 10.1088/0964-1726/20/12/124006.

[19] Jean-Mistral, J., et al. 2008. "Dielectric Polymer: Scavenging Energy from Human Motion.” In Proc. SPIE 6927, Electroactive Polymer Actuators and Devices (EAPAD) 2008, San Diego, CA, 6927, 692716, 1. DOI: $10.1117 / 12.776879$.

[20] Jin, S., Koh, A., Zhao, X., and Suo, Z. 2009. "Maximal
Energy That can be Converted by a Dielectric Elastomer Generator." Applied Physics Letters 94, 262902. DOI: 10.1063/1.3167773

[21] Huang, J., Shian, S., Suo, Z., and Clarke, D. 2013. "Maximizing the Energy Density of Dielectric Elastomer Generators Using Equi-Biaxial Loading." Adv. Funct. Mater. 23 (40), 5056-61. DOI: 10.1002/adfm.201300402.

[22] Van Kessel, R., Wattez, A., and Bauer, P. 2015. "Analyses and Comparison of an Energy Harvesting System for Dielectric Elastomer Generators Using a Passive Harvesting Concept: The Voltage-clamped Multi-phase System." In Proceedings of SPIE Smart Structures and Materials + Nondestructive Evaluation and Health Monitoring, 943006.

[23] Bortot, E., and Gei, M. 2015. "Harvesting Energy with Load-Driven Dielectric Elastomer Annular Membranes Deforming Out-of-plane.” Extreme Mech. Lett. 5: 62-73.

[24] Brouchu, P., Li, H., Niu, X., and Pei, Q. 2010. "Factors Influencing the Performance of Dielectric Elastomer Energy Harvester." SPIE, Proc. San Diego, CA, 7642, 7622J. DOI: 10.1117/12.847756.

[25] Kornbluh, R., Pelrine, R., Prahlad, H., Wong-Foy, A., McCoy, B., Kim, S., Eckerle, J., and Low, T. 2011. "From Boots to Buoys: Promises and Challenges of Dielectric Elastomer Energy Harvesting." In Proc. SPIE 7976, Electroactive Polymer Actuators and Devices (EAPAD) 2011, 7967, 797605-1. DOI:10.1117/12.882367.

[26] Jean-Mistral, C., Brasrour, C., and Chaillout, J-J. 2010. "Comparison of Electroactive Polymers for Energy Scavenging Applications." SMS 19 (8). DOI: 10.1088/0964-1726/19/8/085012.

[27] Chiba, S., Waki, M., Wada, T., Hirakawa, Y., Matsuda, K., and Ikoma, T. 2013. "Consistent Ocean Wave Energy Harvesting Using Electroactive Polymer (Dielectric Elastomer) Artificial Muscle Generators." Applied Energy, 104: 497-502. DOI: 10.1016/j.apenergy.2012.10.052.

[28] Chiba, S., Waki, M., Kornbluh, R., and Pelrine, R. 2009. "Innovative Wave Power Generation System Using Electroactive Polymer Artificial Muscles.” Oceans' 2009, Proc. Bremen, Germany, ISBN: 978-1-4244-2522-8, e-ISBN: 978-1-4244-2523-5, IEEE DOI: 10.1109/OCEANS.2009.5278346.

[29] Chiba, S., Waki, M., Masuda, K., Ikoma, T., Osawa, H., and Suwa, Y. 2012. "Innovative Power Generation System for Harvesting Wave Energy." Design for Innovative Value Towards a Sustainable Society. Netherlands: Springer, 1002-7.

[30] Moretti, G., Forehand, D., Vertechy, R., Fontana, M., and Ingram, D. 2015. "Analysis and Design of an Oscillating Water Column Wave Energy Converter With Dielectric Elastomer Power Take-Off." In Proceedings of 
International Conference on Offshore Mechanics and Arctic Engineering-OMAE. OMAE2015-42103 DOI: 10.1115/OMAE2015-42103.

[31] Vertechy, R., Fontana, M., Rosati Papini, G. P., and
Forehand, D. 2014. "Open-access Dielectric Elastomer Material Database." In Proc. SPIE 9056, Electroactive Polymer Actuators and Devices (EAPAD) 2014 90561R. DOI: 10.1117/12.2045053. 